\title{
Premalignant Alterations in the Lipid Composition and Fluidity of Colonic Brush Border Membranes of Rats Administered 1,2 Dimethylhydrazine
}

\author{
Thomas A. Brasitus, Pradeep K. Dudeja, and Rajvir Dahiya \\ Department of Medicine, Michael Reese Hospital and Medical Center, Pritzker School of Medicine, \\ University of Chicago, Chicago, Illinois 60616
}

\begin{abstract}
Dimethylhydrazine (DMH) is a potent procarcinogen with selectivity for the colon. To determine whether alterations in the lipid composition and fluidity of rat colonic brush border membranes existed before the development of DMH-induced colon cancer, rats were injected s.c. with this agent $(20 \mathrm{mg} / \mathrm{kg}$ body weight per wk) or diluent for 5, 10, and 15 wk. Animals were killed at these time periods and brush border membranes were prepared from proximal and distal colonocytes of each group. The "static" and "dynamic" components of fluidity of each membrane were then assessed, by steady-state fluorescence polarization techniques using limiting hindered fluorescence anisotropy and order parameter values of the fluorophore $1,6 \mathrm{di}-$ phenyl-1,3,5-hexatriene (DPH) and fluorescence anisotropy values of DL-2-(9-anthroyl) stearic acid and DL-12-(9-anthroyl) stearic acid, respectively. Membrane lipids were extracted and analyzed by thin-layer chromatography and gas-liquid chromatography. Phospholipid methylation activity in these membranes was also measured using $S$-adenosyl-L-methionine as the methyl donor.

The results of these studies demonstrate that: $(a)$ the lipid composition and both components of fluidity of proximal DMHtreated and control membranes and their liposomes were similar at all time periods examined; (b) at 5, 10, and 15 wk the "dynamic component of fluidity" of distal DMH-treated membranes and their liposomes was found to be higher, similar, and lower, respectively, than their control counterparts; (c) the "static component of fluidity" of distal DMH-treated membranes and their liposomes, however, was similar to control preparations at all three time periods; and $(d)$ alterations in the lipid composition and phospholipid methylation activities appeared to be responsible for these differences in the "dynamic component of fluidity" at these various time periods.
\end{abstract}

\section{Introduction}

Characteristics that serve to distinguish malignant from normal cells include their ability to proliferate independently of normal regulatory mechanisms, invade normal tissue, and metastasize (1). Increasing evidence suggests that these characteristics may be modulated by the nucleus of the tumor cell and surface membranes (1).

Address reprint requests to Dr. Brasitus, Department of Medicine, Division of Gastroenterology, Michael Reese Hospital and Medical Center, 4 K\&K, 31st Street and Lake Shore Drive, Chicago, IL 60616. 1985.

Received for publication 16 April 1985 and in revised form 7 November

J. Clin. Invest.

(c) The American Society for Clinical Investigation, Inc.

$0021-9738 / 86 / 03 / 0831 / 10 \quad \$ 1.00$

Volume 77, March 1986, 831-840
Colorectal cancer is a leading cause of death among adult patients with internal malignancies and is incurable in approximately one-half of the patients at the time of initial diagnosis (2). Prior studies have utilized various chemical carcinogens to induce colonic neoplasia in experimental animals, as a means of investigating some of the biological characteristics of these tumors $(3,4)$. One such carcinogen, 1,2 dimethylhydrazine (DMH), ${ }^{1}$ has been extensively studied. DMH is a colonic procarcinogen that requires metabolic activation within the host to become active (4). This agent in weekly doses of $20 \mathrm{mg} / \mathrm{kg}$ of body weight produces colonic carcinoma in virtually $100 \%$ of animals, with a latency period of $\sim 6 \mathrm{mo}(5-7)$. DMH-induced tumors closely parallel human colon cancer with respect to clinical and pathologic features (4). Furthermore, the vast majority of colonic neoplasms occur distally with this carcinogen, paralleling the distribution of human tumors $(4,8)$. Using this model of experimental colon cancer, several investigators have reported biochemical changes in rat colonic tissue prior to the development of overt tumors $(4,9,10)$. To date, however, similar studies have not been performed in plasma membranes of rat colonocytes. Our laboratory has recently devised techniques for the isolation of brush border $(11)$ and basolateral $(12,13)$ plasma membranes from rat proximal and distal colonocytes. Regional differences have been noted in the lipid fluidity ${ }^{2}$ and lipid composition of these colonic antipodal plasma membranes $(12,13)$.

Considerable attention has been focused on membrane lipid fluidity and its relationship to the malignant transformation process. Several laboratories have reported alterations in the fluidity of cancer cells (15-17). The present studies were, therefore, undertaken to examine whether changes in the "static and dynamic components of fluidity" and lipid composition exist in brush border membranes prepared from colonocytes of animals treated with DMH for 5, 10, and 15 wk, i.e., before the development of colonic cancer. In view of the regional differences previously noted in these parameters as well as the predilection for the development of distal tumors with $\mathrm{DMH}$, both proximal and distal plasma membranes were examined in these studies. The data from these experiments demonstrate that "premalignant" alterations in the dynamic component of fluidity and lipid

1. Abbreviations used in this paper: 2-AS, DL-2-(9-anthroyl) stearic acid; 12-AS, DL-12-(9-anthroyl) stearic acid; DMH, 1,2 dimethylhydrazine; DPH, 1,6 diphenyl-1,3,5-hexatriene.

2. The term "lipid fluidity" as applied to anisotropic bilayer membranes is used to denote the relative motional freedom of the lipid molecules or substituents thereof. A more detailed description of the sense in which the term is used is given in Schachter et al. (14). Briefly, as evaluated by steady-state fluorescence polarization of lipid fluorophors, fluidity is assessed via the parameters of the modified Perrin relationship described in Methods. An increase in fluidity corresponds to a decrease in either the correlation time, $T_{c}$, or the hindered anisotropy, $r_{\infty}$, of the fluorophore. Hence, the term combines the concepts of the "dynamic and static (lipid order) components" of fluidity. 
composition of distal brush border membranes can be detected and serve as the basis for the present report.

\section{Methods}

Isolation of proximal and distal colonic epithelial cell brush border membranes. Male albino rats of the Sherman strain weighing 75-100 g were given weekly s.c. injections of diluent or 1,2 dimethylhydrazine dihydrochloride (Sigma Chemical Co., St. Louis, MO) at a dose of $20 \mathrm{mg} /$ $\mathrm{kg}$ body weight for 5,10 , and $15 \mathrm{wk}$. The stock solution for injections consisted of $400 \mathrm{mg}$ of DMH dissolved in $100 \mathrm{ml}$ of water containing $37 \mathrm{mg}$ EDTA and was adjusted to $\mathrm{pH} 6.5$ with sodium hydroxide (18). The animals were maintained on a pelleted diet (Camm Maintenance Rodent Diet, Camm Research Institute, Inc., Wayne, NJ) with water and food ad libitum. At 5-wk intervals, control and DMH-treated animals were fasted for $18 \mathrm{~h}$ with water ad libitum before sacrifice. For each control or DMH-treated preparation, six animals were killed rapidly by cervical dislocation and their colons were excised. The cecum from each animal was discarded, and the remaining large intestine divided into two parts: proximal and distal (19). Epithelial cells, relatively devoid of goblet cells, were then obtained from each segment using a technique that combined chelation of divalent cations with mild mechanical dissociation as described (11-13).

The cells from each segment were then pooled separately and used to isolate brush border membranes as previously described (11). The purity of each membrane preparation was assessed by the marker enzymes total alkaline phosphatase ( $p$-nitro-phenylphosphatase) and cysteinesensitive alkaline phosphatase (11); specific activity ratios [(purified membrane)/(original homogenates)] ranged from 16 to 20 for these enzymes (Table I). The corresponding values for NADPH cytochrome $c$ reductase, succinic dehydrogenase, and sodium, potassium-dependent adenosine triphosphatase, marker enzymes for microsomal, mitochondrial, and basolateral membranes, respectively, ranged from 0.50 to 1.50 in each of these membrane preparations (11). Protein was estimated by the method of Lowry et al. (20). Liposomes were prepared from the extracted lipids of each membrane as previously described (21).

Fluorescence polarization studies. Three fluorophores were used: 1,6 diphenyl-1,3,5-hexatriene (DPH), DL-2-(9-anthroyl) stearic acid (2-AS), and DL-12-(9-anthroyl) stearic acid (12-AS). All compounds were obtained from Aldrich Chemical Co. (Milwaukee, WI) or Molecular Probes Inc. (Junction City, OR). Steady-state fluorescence polarization studies were performed using a Perkin-Elmer 650-40 spectrofluorometer (PerkinElmer Corp., Norwalk, CT) adapted for fluorescence polarization. The methods used to load the membranes and liposomes and the quantification of the polarization of fluorescence have been described (21-25). In this regard, however, it should be noted that, as evaluated by steadystate fluorescence polarization of lipid fluorophores, "fluidity" has usually been assessed via the fluorescence anisotropy $r$, without further resolution of the compenents that determine $r$. Recent studies with the rodlike fluorophore DPH, however, have demonstrated that the rotations of this probe are hindered in both artificial and biological membranes (26-28). Therefore, the fluorescence anisotropy of such a fluorophore is not adequately described by the Perrin equation but by a modified relationship (29, 30): $r=r_{\infty}+\left(r_{0}-r_{\infty}\right)\left[T_{\mathrm{c}} /\left(T_{\mathrm{c}}+T_{\mathrm{f}}\right)\right]$, where $r$ is the fluorescence anisotropy, $r_{0}$ is the maximal limiting anisotropy, taken as 0.365 for DPH and 0.285 for the anthroyl probes (25), $r_{\infty}$ is the limiting hindered anisotropy, $T_{\mathrm{c}}$ is the correlation time, and $T_{\mathrm{f}}$ is the mean lifetime of the excited state. The $r_{\infty}$ values of DPH in natural and artificial bilayer membranes are high and largely determine $r(14,31)$. The $r_{\infty}$ values of DPH can also be used to define an order parameter, $S$, where $S=\left(r_{\infty} /\right.$ $\left.r_{0}\right)^{1 / 2}(29,30)$. The $r_{\infty}$ and $S$ values of DPH can, therefore, be used to assess the "static component of fluidity" of membranes. Unlike DPH, the anthroyl probes (2-AS and 12-AS) yield relatively low values of $r_{\infty}$ in bilayer membranes $(14,31)$. Their $r$ values reflect mainly $T_{\mathrm{c}}$, the speed of rotation, and can be used to assess the "dynamic component of fluidity" of membranes.

Table I. Purification of Brush Border Membranes of Proximal and Distal Colonocytes after 5, 10, and 15 wk of Administration of DMH or Diluent Assessed by the Specific Activities of the Marker Enzymes Alkaline Phosphatase and Cysteine-sensitive Alkaline Phosphatase*

\begin{tabular}{|c|c|c|c|c|c|c|}
\hline \multirow[b]{3}{*}{ Duration of treatment } & \multirow[b]{3}{*}{ Preparations } & \multirow[b]{3}{*}{$n$} & \multicolumn{4}{|c|}{ Specific activity of marker enzyme } \\
\hline & & & \multicolumn{2}{|l|}{ Proximal } & \multicolumn{2}{|l|}{ Distal } \\
\hline & & & AP & CSAP & AP & CSAP \\
\hline \multirow[t]{3}{*}{$w k$} & & & \multicolumn{4}{|c|}{ nmol $\mathrm{mg}^{-1}$ protein $\mathrm{min}^{-1}$} \\
\hline & Control homogenate & 10 & $18.3 \pm 1.0$ & $16.5 \pm 0.9$ & $15.6 \pm 1.3$ & $13.3 \pm 1.2$ \\
\hline & Control membrane & 10 & $328.6 \pm 11.2$ & $280.3 \pm 8.2$ & $256.3 \pm 10.6$ & $217.1 \pm 9.8$ \\
\hline \multirow[t]{6}{*}{5} & & & $(18)$ & (17) & $(16)$ & $(16)$ \\
\hline & DMH homogenate & 10 & $20.6 \pm 0.8$ & $17.6 \pm 0.7$ & $15.2 \pm 1.2$ & $13.8 \pm 1.1$ \\
\hline & DMH membrane & 10 & $331.3 \pm 7.6$ & $281.2 \pm 9.7$ & $261.4 \pm 11.8$ & $220.3 \pm 12.2$ \\
\hline & & & (16) & (16) & (17) & (16) \\
\hline & Control homogenate & 10 & $19.4 \pm 1.1$ & $15.8 \pm 1.2$ & $15.0 \pm 1.1$ & $12.2 \pm 1.2$ \\
\hline & Control membrane & 10 & $316.4 \pm 12.1$ & $273.4 \pm 11.2$ & $254.2 \pm 6.7$ & $211.3 \pm 1.2$ \\
\hline \multirow[t]{6}{*}{10} & & & $(16)$ & (17) & (17) & (17) \\
\hline & DMH homogenate & 10 & $18.2 \pm 1.3$ & $15.8 \pm 1.2$ & $13.6 \pm 1.7$ & $11.3 \pm 8.3$ \\
\hline & DMH membrane & 10 & $310.7 \pm 15.6$ & $268.3 \pm 14.3$ & $248.3 \pm 11.7$ & $207.6 \pm 9.9$ \\
\hline & & & (17) & (17) & (18) & (18) \\
\hline & Control homogenate & 8 & $19.1 \pm 1.6$ & $16.3 \pm 1.5$ & $13.1 \pm 1.3$ & $11.2 \pm 1.1$ \\
\hline & Control membrane & 8 & $326.3 \pm 9.6$ & $277.6 \pm 10.3$ & $260.0 \pm 14.3$ & $221.1 \pm 13.9$ \\
\hline \multirow[t]{4}{*}{15} & & & (17) & (17) & (20) & (20) \\
\hline & DMH homogenate & 8 & $16.9 \pm 1.5$ & $14.3 \pm 1.6$ & $13.6 \pm 1.4$ & $10.7 \pm 1.4$ \\
\hline & DMH membrane & 8 & $324.7 \pm 10.6$ & $268.3 \pm 11.5$ & $256.7 \pm 11.7$ & $215.4 \pm 10.2$ \\
\hline & & & (19) & (19) & (19) & $(20)$ \\
\hline
\end{tabular}

* Values represent means \pm standard error of number of preparations indicated under $n$. Numbers in parentheses represent fold purifications of membrane values compared to starting homogenate values. Abbreviations: AP, alkaline phosphatase; CSAP, cysteine-sensitive alkaline phosphatase. 
In the present studies $r_{\infty}$ values for DPH were calculated from $r$ values as previously described by Van Blitterswijk et al. (32). The content of each fluorophore in the membranes and liposomes was estimated fluorometrically as described by Cogan and Schachter (33). Final molar ratios of probe/lipid ranged from 0.001 to 0.002 and the anisotropy differences noted in these studies could not be ascribed to differences in probe concentration in the preparations. Corrections for light scattering (suspensions minus probe) and for fluorescence in the ambient medium (quantified by pelleting the preparations after each estimation) were made routinely, and the combined corrections were $<3 \%$ of the total fluorescence intensity observed for DPH-loaded preparations and $<5 \%$ of that observed for anthroylstearate-loaded suspensions. No changes in the excited-state lifetimes, as assessed by total fluorescence intensity were demonstrated using each probe in each membrane or liposome preparations (19-25).

Composition studies. Total lipids were extracted from the membranes by the method of Folch et al. (34). Cholesterol and phospholipids were measured by the methods of Zlatkis et al. (35) and Ames and Dubin (36), respectively. The phospholipid composition of the extracts was further examined by thin-layer chromatography according to the procedure of Katz et al. (37). Fatty acids of the total lipid extracts were derivatized as described by Gartner and Vahouny (38). Fatty acid methyl esters were determined on a Hewlett-Packard 5790A gas-liquid chromatograph (Hewlett-Packard Co., Palo Alto, CA) equipped with a flame ionization detector and interfaced with a Hewlett-Packard 3390A integrator, using authentic fatty acid methyl esters to identify retention times (38).

Assay of phospholipid methylation. The methylation of phospholipids was measured by incorporation of the $\left[{ }^{3} \mathrm{H}\right]$ methyl group from $S$-adenosyl$\mathrm{L}-\left[\right.$ methyl $\left.{ }^{3} \mathrm{H}\right]$ methionine $(5.0-15.0 \mathrm{Ci} / \mathrm{mmol})$ into phospholipids $(39$, 40). The reaction mixture $(500 \mu \mathrm{l})$ contained buffer $(50 \mathrm{mM}$ Tris-acetate, pH 8.0), S-adenosyl-L-[methyl $\left.-{ }^{3} \mathrm{H}\right]$ methionine $[200 \mu \mathrm{M}, 4 \mu \mathrm{Ci}]$ and plasma membranes ( $200 \mu \mathrm{g}$ of protein). The reaction was initiated by the addition of membranes and run at $37^{\circ} \mathrm{C}$ for $60 \mathrm{~min}$, unless otherwise indicated. The reaction was terminated by addition of $3 \mathrm{ml}$ of chloroform/ methanol/2 $\mathrm{N}$ hydrochloric acid (6:3:1, vol/vol) followed by addition of $2 \mathrm{ml}$ of $0.1 \mathrm{M} \mathrm{KCl}$ in $50 \%$ methanol. The mixture was vigorously vortexed twice and then centrifuged at $200 \mathrm{~g}$ for $10 \mathrm{~min}$. The aqueous phase was aspirated, the chloroform phase washed with $2 \mathrm{ml}$ of $0.1 \mathrm{M} \mathrm{KCl}$ in $50 \%$ methanol, and $1 \mathrm{ml}$ of the chloroform phase was transferred to a scintillation vial. After the solvent was evaporated to dryness under a stream of nitrogen, $10 \mathrm{ml}$ of ACS scintillation fluid (Amersham Corp., Arlington Heights, IL) was added and the radioactivity was measured in a Beckman LS 6800 liquid scintillation system (Beckman Instrument Corp., Palo Alto, CA).

To identify the products of phospholipid methylation, the chloroform phase was evaporated to dryness under nitrogen gas at $25^{\circ} \mathrm{C}$ and the residue dissolved in $100 \mu \mathrm{l}$ of chloroform. The sample was applied on a silica Gel G plate and the chromatogram developed in chloroform/propionic acid/n-propyl alcohol/water $(2: 2: 3: 1, \mathrm{vol} / \mathrm{vol})$ at $23^{\circ} \mathrm{C}$ in ascending mode. The phospholipid standards were chromatographed simultaneously and their positions visualized by exposure to iodine vapors. The areas corresponding to the standard phospholipids (phosphatidylethanolamine, phosphatidyl- $N$-monomethylethanolamine, phosphatidyldimethylethanolamine, and phosphatidylcholine) were scraped separately and extracted with chloroform/methanol (2:1, vol/vol), and radioactivity was quantified as described above.

The chemical identity of the methylated products was further established by two-dimensional chromatography (41) and by hydrolysis of the phospholipids and identification of their free bases as described by Schneider and Vance (42). Additionally, both labeled and unlabeled $S$ adenosyl-L-methionine were routinely purified by ion-exchange before use (43).

Histological studies. At 5, 10, and 15 wk 1-cm proximal and distal colonic segments from each control and DMH-treated animal killed were immediately fixed in $4 \%$ paraformaldehyde. Fixed specimens were then embedded in paraffin for light microscopic examination and stained with hematoxylin and eosin (18).

Statistical methods. All results are expressed as mean values \pm standard error. Paired or unpaired $t$ tests were used for all statistical analysis. A $P$ value $<0.05$ was considered significant.

Materials. $S$-adenosyl-L-[methyl $\left.-^{3} \mathrm{H}\right]$ methionine $(5.0-15.0 \mathrm{Ci} / \mathrm{mmol})$ was obtained from New England Nuclear (Boston, MA). Fatty acids, methyl esters, gas-liquid chromatography columns and lipid standards were all purchased from Applied Science Corp. (State College, PA) and/ or Supelco (Bellefonte, PA). All other materials were obtained from either Fisher Chemical Co. (Fairlawn, NJ) or Sigma Chemical Co. unless otherwise indicated.

\section{Results}

Light microscopic studies. Earlier light microscopic studies (4, 7) conducted on the effect of DMH on colonic epithelial histology have revealed that with the present regimen used for administration of DMH $(20 \mathrm{mg} / \mathrm{kg}$ body weight per wk), severe atypia or carcinoma in situ did not appear until at least 14-16 wk, microscopic adenocarcinomas developed between 12 and $18 \mathrm{wk}$, and visible adenocarcinomas were present in the majority of animals by $18-24 \mathrm{wk}$. Despite extensive sampling of the proximal and distal segments of colon in control and DMH-treated animals, no evidence of severe atypia, carcinoma in situ, or microscopic adenocarcinomas were evident at 5, 10, or 15 wk by light microscopic examination. A representative example of the histologic appearance of the distal segment of rat colonic mucosa after 15 wk of DMH treatment is shown in Fig. 1.

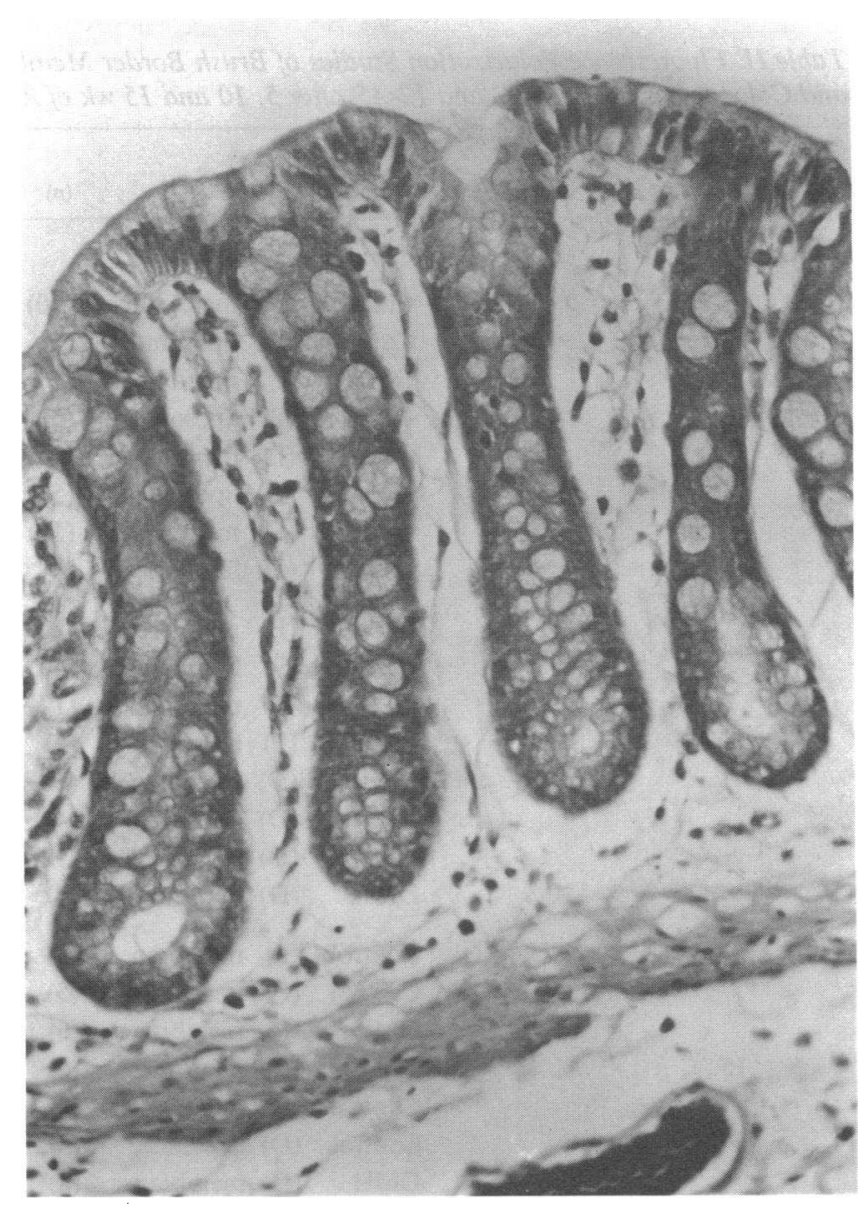

Figure 1. Typical light microscopic appearance of distal colonic mucosa after 15 wk of DMH treatment. Severe atypia, carcinoma in situ, or microscopic adenocarcinoma is not evident. (hematoxylin and eosin, $\times 183$ ) (original magnification). 
Other investigators have also reported that $\mathrm{DMH}$ administration can cause inflammation of the colon which may later subside (44). In the present study, minimal inflammation was noted in the proximal and distal colonic segments, was equally distributed in these segments, and did not appear to differ in intensity after 5,10 , and 15 wk of treatment with DMH. It is, therefore, unlikely that inflammation per se was responsible for the biochemical alterations noted in the distal DMH-treated membranes (see below).

Fluorescence polarization studies. The static and dynamic components of lipid fluidity of brush border membranes and their liposomes prepared from proximal and distal colonocytes of control and DMH-treated rats at 5, 10, and 15 wk were assessed by steady-state fluorescence polarization techniques, utilizing $r_{\infty}$ and $S$ values of DPH and $r$ values of 2-AS and 12-AS, respectively. The results of these studies are summarized in Tables II and III. As can be seen from these tables, both components of lipid fluidity of proximal control and DMH-treated membranes and their liposomes were similar at each time point using the three fluorophores. Microvillus membranes prepared from control and DMH-treated enterocytes of the small intestine also had similar fluidity values at all time points using these probes (not shown). As shown in Table II, however, this was not found to be true for distal colonic membranes and their liposomes. As assessed by the $r$ values of 2-AS and 12-AS, at 5 wk distal DMHtreated membranes and liposomes were more fluid than their distal control counterparts. At $10 \mathrm{wk}$, the fluidity of these membranes and liposomes was similar. By 15 wk, distal DMH-treated membranes and liposomes were less fluid than their control counterparts. The ratio of $r_{\mathrm{DMH}} / r_{\text {control }}$ for both anthroyl probes, therefore, progressively increased in distal membranes from 5 to 15 wk (Fig. 2). Thus, the dynamic component of fluidity of DMH-treated membranes, relative to control membranes became progressively less in this colonic segment over $15 \mathrm{wk}$. The static component of fluidity of these distal membranes and their liposomes, however, as assessed by $r_{\infty}$ and $S$ values of DPH, were similar at all time points (Table III).

Because DMH has been shown to increase the rate of renewal of the colonic epithelium (4), it was conceivable that some of our results could have been influenced by altered colonocyte populations. If, for example, "younger" cells (closer to the crypts) contained brush border membranes with different 2-AS and 12AS anisotropy values, changes in proliferative rates could influence fluidity determinations. To test this possibility, we used a method previously described by our laboratory $(45)$ to isolate two populations of colonocytes, "older" cells (closer to the surface) and "younger" cells from the crypt region. Brush border membranes were prepared from these cells and estimations of

Table II. Fluorescence Polarization Studies of Brush Border Membranes and Liposomes of Proximal and Colonocytes Using 2-AS and 12-AS after 5, 10 and 15 wk of Administration of DMH or Diluent*

\begin{tabular}{|c|c|c|c|c|c|}
\hline $\begin{array}{l}\text { Duration of } \\
\text { treatment }\end{array}$ & \multicolumn{2}{|c|}{ Preparations } & $(n)$ & $\begin{array}{l}\text { 2-AS Anisotropy, } \\
r \text { at } 25^{\circ} \mathrm{C}\end{array}$ & $\begin{array}{l}\text { 12-AS Anisotropy, } \\
r \text { at } 25^{\circ} \mathrm{C}\end{array}$ \\
\hline & Control & (P) $\ddagger$ membranes & $(10)$ & $0.113 \pm 0.002$ & $0.103 \pm 0.002$ \\
\hline & Control & (P) liposomes & (5) & $0.085 \pm 0.003$ & $0.077 \pm 0.003$ \\
\hline & $\mathrm{DMH}$ & (P) membranes & $(10)$ & $0.113 \pm 0.001$ & $0.105 \pm 0.001$ \\
\hline \multirow[t]{8}{*}{5} & DMH & (P) liposomes & (5) & $0.084 \pm 0.002$ & $0.078 \pm 0.002$ \\
\hline & Control & (D) membranes & (10) & $0.114 \pm 0.002$ & $0.112 \pm 0.002$ \\
\hline & Control & (D) liposomes & (5) & $0.087 \pm 0.002$ & $0.085 \pm 0.002$ \\
\hline & DMH & (D) membranes & (10) & $0.102 \pm 0.002 \S$ & $0.100 \pm 0.002 \S$ \\
\hline & $\mathrm{DMH}$ & (D) liposomes & $(5)$ & $0.078 \pm 0.001 \S$ & $0.076 \pm 0.002 \S$ \\
\hline & Control & (P) membranes & $(12)$ & $0.105 \pm 0.002$ & $0.098 \pm 0.001$ \\
\hline & Control & (P) liposomes & (4) & $0.078 \pm 0.001$ & $0.074 \pm 0.002$ \\
\hline & $\mathrm{DMH}$ & (P) membranes & (12) & $0.104 \pm 0.002$ & $0.097 \pm 0.001$ \\
\hline \multirow[t]{8}{*}{10} & $\mathrm{DMH}$ & (P) liposomes & (4) & $0.077 \pm 0.003$ & $0.074 \pm 0.002$ \\
\hline & Control & (D) membranes & (12) & $0.110 \pm 0.001$ & $0.103 \pm 0.001$ \\
\hline & Control & (D) liposomes & (4) & $0.083 \pm 0.002$ & $0.077 \pm 0.001$ \\
\hline & DMH & (D) membranes & (12) & $0.110 \pm 0.001$ & $0.104 \pm 0.001$ \\
\hline & $\mathrm{DMH}$ & (D) liposomes & (4) & $0.083 \pm 0.002$ & $0.078 \pm 0.002$ \\
\hline & Control & (P) membranes & (8) & $0.108 \pm 0.005$ & $0.107 \pm 0.003$ \\
\hline & Control & (P) liposomes & (5) & $0.080 \pm 0.002$ & $0.080 \pm 0.003$ \\
\hline & $\mathrm{DMH}$ & (P) membranes & (8) & $0.111 \pm 0.002$ & $0.110 \pm 0.002$ \\
\hline \multirow[t]{5}{*}{15} & DMH & (P) liposomes & (5) & $0.082 \pm 0.003$ & $0.083 \pm 0.002$ \\
\hline & Control & (D) membranes & (8) & $0.110 \pm 0.002$ & $0.108 \pm 0.002$ \\
\hline & Control & (D) liposomes & (5) & $0.081 \pm 0.002$ & $0.080 \pm 0.002$ \\
\hline & DMH & (D) membranes & (8) & $0.120 \pm 0.001 \S$ & $0.118 \pm 0.001 \S$ \\
\hline & DMH & (D) liposomes & (5) & $0.094 \pm 0.002 \S$ & $0.092 \pm 0.002 \S$ \\
\hline
\end{tabular}

\footnotetext{
* Values represent means \pm standard error. $\ddagger$ Abbreviations: $\mathrm{D}$, distal; $\mathrm{P}$, proximal. $\S P<0.05$ or less compared to control membrane or liposome values of same colonic segment.
} 
Table III. Fluorescence Polarization Studies of Brush Border Membrane and Liposomes of Proximal and Distal Colonocytes Using DPH after 5, 10 and 15 wk of Administration of DMH or Diluent*

\begin{tabular}{|c|c|c|c|c|c|c|}
\hline $\begin{array}{l}\text { Duration of } \\
\text { treatment }\end{array}$ & Preparation & & $(n)$ & $\begin{array}{l}\text { Anisotropy, } \\
r \text { at } 25^{\circ} \mathrm{C}\end{array}$ & $\begin{array}{l}\text { Limiting hindered } \\
\text { anisotropy, } \\
r_{\infty} \text { at } 25^{\circ} \mathrm{C}\end{array}$ & $\begin{array}{l}\text { Order parameter, } \\
S \text { at } 25^{\circ} \mathrm{C}\end{array}$ \\
\hline \multicolumn{7}{|l|}{$w k$} \\
\hline \multirow{8}{*}{5} & Control & (P) $\ddagger$ membranes & (10) & $0.216 \pm 0.004$ & $0.188 \pm 0.004$ & $0.718 \pm 0.007$ \\
\hline & Control & (P) liposomes & $(5)$ & $0.163 \pm 0.005$ & $0.117 \pm 0.005$ & $0.566 \pm 0.007$ \\
\hline & DMH & (P) membranes & (10) & $0.212 \pm 0.005$ & $0.183 \pm 0.005$ & $0.708 \pm 0.009$ \\
\hline & DMH & (P) liposomes & (5) & $0.161 \pm 0.005$ & $0.115 \pm 0.006$ & $0.561 \pm 0.009$ \\
\hline & Control & (D) membranes & (10) & $0.244 \pm 0.004$ & $0.225 \pm 0.003$ & $0.785 \pm 0.006$ \\
\hline & Control & (D) liposomes & (5) & $0.184 \pm 0.004$ & $0.145 \pm 0.005$ & $0.630 \pm 0.009$ \\
\hline & DMH & (D) membranes & (10) & $0.241 \pm 0.005$ & $0.221 \pm 0.005$ & $0.778 \pm 0.009$ \\
\hline & DMH & (D) liposomes & (5) & $0.182 \pm 0.005$ & $0.143 \pm 0.005$ & $0.626 \pm 0.008$ \\
\hline \multirow{8}{*}{10} & Control & (P) membranes & (12) & $0.217 \pm 0.002$ & $0.189 \pm 0.003$ & $0.720 \pm 0.005$ \\
\hline & Control & (P) liposomes & (4) & $0.162 \pm 0.004$ & $0.116 \pm 0.005$ & $0.564 \pm 0.008$ \\
\hline & DMH & (P) membranes & (12) & $0.221 \pm 0.004$ & $0.195 \pm 0.004$ & $0.731 \pm 0.007$ \\
\hline & DMH & (P) liposomes & (4) & $0.164 \pm 0.003$ & $0.119 \pm 0.004$ & $0.571 \pm 0.008$ \\
\hline & Control & (D) membranes & $(12)$ & $0.234 \pm 0.002$ & $0.212 \pm 0.002$ & $0.762 \pm 0.004$ \\
\hline & Control & (D) liposomes & (4) & $0.176 \pm 0.003$ & $0.135 \pm 0.003$ & $0.608 \pm 0.007$ \\
\hline & DMH & (D) membranes & (12) & $0.234 \pm 0.004$ & $0.212 \pm 0.003$ & $0.762 \pm 0.006$ \\
\hline & DMH & (D) liposomes & $(4)$ & $0.175 \pm 0.004$ & $0.133 \pm 0.004$ & $0.604 \pm 0.007$ \\
\hline \multirow{8}{*}{15} & Control & (P) membranes & (10) & $0.217 \pm 0.006$ & $0.189 \pm 0.008$ & $0.719 \pm 0.009$ \\
\hline & Control & (P) liposomes & (5) & $0.163 \pm 0.004$ & $0.117 \pm 0.005$ & $0.567 \pm 0.009$ \\
\hline & DMH & (P) membranes & (10) & $0.226 \pm 0.004$ & $0.201 \pm 0.004$ & $0.742 \pm 0.008$ \\
\hline & DMH & (P) liposomes & $(5)$ & $0.167 \pm 0.004$ & $0.123 \pm 0.005$ & $0.580 \pm 0.009$ \\
\hline & Control & (D) membranes & $(10)$ & $0.242 \pm 0.003$ & $0.223 \pm 0.003$ & $0.782 \pm 0.006$ \\
\hline & Control & (D) liposomes & $(5)$ & $0.180 \pm 0.003$ & $0.140 \pm 0.004$ & $0.619 \pm 0.008$ \\
\hline & DMH & (D) membranes & $(10)$ & $0.245 \pm 0.002$ & $0.227 \pm 0.002$ & $0.789 \pm 0.005$ \\
\hline & DMH & (D) liposomes & $(5)$ & $0.182 \pm 0.003$ & $0.143 \pm 0.003$ & $0.625 \pm 0.006$ \\
\hline
\end{tabular}

* Values represent means \pm standard error. $¥$ Abbreviations: $D$, distal; P, proximal.

the 2-AS and 12-AS anisotropy values revealed no difference in fluidity (not shown). These results, therefore, excluded more rapid renewal as an explanation for our observations.

Phospholipid methylation studies. Our laboratory has recently demonstrated that phospholipid methylation activity in rat colonic brush border membranes can increase the lipid fluidity of this membrane (46). It was, therefore, of interest to examine phospholipid methylation activity in colonic brush border membranes of control and DMH-treated animals. As shown in Table IV, phospholipid methyltransferase specific activity was similar in proximal membranes prepared from both groups of animals at all three time points examined.

DMH-treated distal brush border membranes, however, possessed significantly higher activity than control membranes at 5, 10, and $15 \mathrm{wk}$ (Table IV). Evaluation of the kinetic parameters of the enzymatic activities in both distal membranes by double reciprocal plots (47), revealed that the enzyme in DMHtreated membranes had higher maximal velocity $\left(V_{\max }\right)$ values, but similar $K_{\mathrm{m}}$ values at each time period (Table IV).

It was conceivable that a separate methyltransferase with similar $K_{\mathrm{m}}$ but different $V_{\max }$ values was induced by DMH treatment in these distal membranes $(4,9,19)$. The enzyme present in DMH-treated membranes, however, was found to possess the same $\mathrm{pH}$ optimum (pH 8.0) as its control counterpart, and its activity was similarly influenced by $0.05 \%$ Triton X-100 (stim- ulated by $20 \%$ ), $10 \mathrm{mM}$ ATP (75\% inhibition), and trypsin treatment (20\% inhibition) as previously described for the distal colonic control methyltransferase (46). Although these observations do not totally exclude the possibility that the methyltransferase present in DMH-treated membranes is a separate enzyme, they do suggest that this is unlikely. Further studies will be necessary, however, to clarify this issue.

Lipid composition studies. Prior studies in model bilayers and natural membranes have correlated a high lipid fluidity with low molar ratios of cholesterol/phospholipid and sphingomyelin/ lecithin (48-51). A low ratio of protein/lipid (wt/wt) (21) as well as less saturated or shorter fatty acyl chains in phospholipids $(50,52)$, also has been associated with a higher membrane lipid fluidity. It was, therefore, of interest to examine these parameters in brush border membranes prepared from proximal and distal colonocytes of control and DMH-treated animals at 5, 10, and $15 \mathrm{wk}$. The results of these studies are summarized in Table V. At each time period, proximal control and DMH-treated membranes possessed similar values for all parameters evaluated. This was also the case for distal membranes at $5 \mathrm{wk}$. At $10 \mathrm{wk}$, however, both the sphingomyelin content (Table VI) and the sphingomyelin/lecithin molar ratio (Table V) were greater in distal DMH-treated brush border membranes as compared to their control membrane counterparts. At $15 \mathrm{wk}$, distal DMH-treated membranes again had a greater sphingomyelin content and 

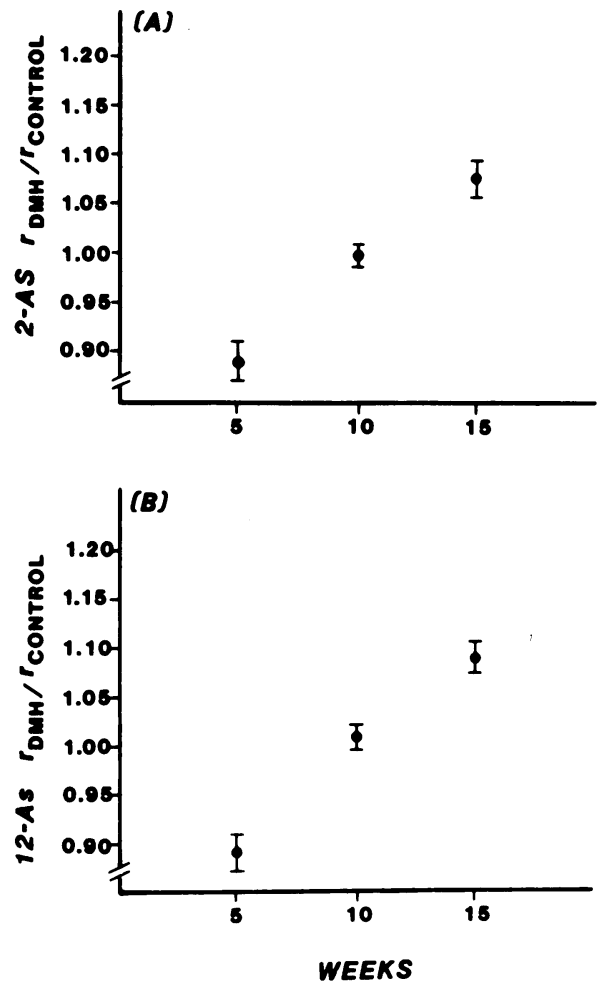

Figure 2. Ratio of the fluorescence anisotropy, $r$, at $25^{\circ} \mathrm{C}$ in DMHtreated and control distal brush border membranes at the time periods indicated, as assessed by steady-state fluorescence polarization using the fluorophores $(A)$ DL-2-(9-anthroyl) stearic acid (2-AS) and $(B)$ DL12-(9-anthroyl) stearic acid (12-AS).

sphingomyelin/lecithin molar ratio than control membranes. They also possessed a higher saturation index (Table V). This was due to a decrease in arachidonic acid (20:4) in the DMHtreated membranes compared to controls (Table VII).

\section{Discussion}

The experimental results demonstrate that alterations in the dynamic component of fluidity of brush border membranes and their liposomes could be detected in the preneoplastic colon of rats after the administration of the chemical carcinogen DMH. These changes were restricted to membranes and liposomes prepared from distal colonocytes and, furthermore, varied with duration of administration (5-15 wk) of this agent.

Differences in the dynamic component of fluidity of control and DMH-treated distal membranes and their liposomes were seen at the earliest time period examined, i.e., after $5 \mathrm{wk}$ of DMH. At this time, DMH-treated membranes and liposomes were found to be more fluid than their control counterparts. Analysis of compositional parameters previously shown to correlate with differences in membrane fluidity $(21,48-52,53)$, however, revealed that both membranes possessed similar values for each parameter. Because previous studies had demonstrated increases in a number of enzymatic activities in preneoplastic colonic tissue of DMH-treated animals $(4,9,10)$, phospholipid methyltransferase activity was analyzed in both membranes. This latter enzyme was of particular interest because our laboratory had recently correlated increases in its activity with increases in rat colonic brush border membrane fluidity (46). The activity of this enzyme was found to be significantly increased in distal DMH-treated membranes compared to distal control membranes. In both proximal membranes, however, methyltransferase activity was similar. Evaluation of kinetic parameters from double reciprocal plots (47), moreover, demonstrated a higher $V_{\max }$ for this enzyme in DMH-treated distal membranes than control membranes but similar $K_{\mathrm{m}}$ values. It bears emphasis, however, that the number of enzyme units was not monitored in these studies. Hence, these alterations in the DMH-treated membranes could result from changes in the number of enzyme units as well as from alterations in the function of each unit.

The relationship of this increased methyltransferase activity to the fluidity changes noted in the distal DMH-treated membranes remains unclear at this time. Although it is certainly possible that the increase in its activity might, at least partially, be responsible for the increased dynamic component of fluidity seen in the 5-wk distal DMH-membranes, based on prior observations in our laboratory (46) and others (54), it was surprising that it did not influence the static component of fluidity as well. Additionally, the content of phosphatidylethanolamine and

Table IV. Phospholipid Methyltransferase Specific Activities and Kinetic Parameters in Brush Border Membranes of Rat Proximal and Distal Colonocytes after 5, 10, and 15 wk of Administration of DMH or Diluent*

\begin{tabular}{|c|c|c|c|c|c|}
\hline \multirow{2}{*}{$\begin{array}{l}\text { Duration of } \\
\text { treatment }\end{array}$} & \multirow{2}{*}{$\begin{array}{l}\text { Specific activities and } \\
\text { kinetic parametersł }\end{array}$} & \multicolumn{2}{|l|}{ Proximal } & \multicolumn{2}{|l|}{ Distal } \\
\hline & & Control & DMH & Control & DMH \\
\hline \multicolumn{6}{|l|}{$w k$} \\
\hline \multirow{4}{*}{5} & Sp act & $447.9 \pm 11.9$ & $449.5 \pm 41.3$ & $336.8 \pm 30.5$ & $475.3 \pm 12.0 \S$ \\
\hline & $V_{\max }$ & - & - & $438.7 \pm 40.1$ & $758.4 \pm 21.4 \S$ \\
\hline & $K_{\mathrm{m}}$ & - & - & $111.3 \pm 6.8$ & $105.1 \pm 9.7$ \\
\hline & Sp act & $442.0 \pm 29.6$ & $374.5 \pm 48.1$ & $338.0 \pm 10.1$ & $575.5 \pm 29.0 \S$ \\
\hline \multirow[t]{3}{*}{10} & $V_{\max }$ & - & - & $467.7 \pm 30.7$ & $752.4 \pm 39.3 \S$ \\
\hline & $K_{\mathrm{m}}$ & - & - & $103.6 \pm 10.2$ & $112.1 \pm 11.9$ \\
\hline & Sp act & $420.5 \pm 13.3$ & $465.4 \pm 13.7$ & $304.0 \pm 30.1$ & $474.2 \pm 36.0 \S$ \\
\hline \multirow[t]{2}{*}{15} & $V_{\max }$ & - & - & $400.1 \pm 43.2$ & $741.3 \pm 18.6 \S$ \\
\hline & $\widehat{K_{\mathrm{m}}}$ & - & - & $99.4 \pm 11.1$ & $110.6 \pm 12.4$ \\
\hline
\end{tabular}

* Values represent means \pm standard error of six separate preparations of each membrane. $¥$ Values for specific activity and $V_{\max }:$ pmol/mg protein per $\mathrm{h}$. Values for $K_{\mathrm{m}}: \mu \mathrm{M}$. $\S P<0.05$ or less compared to control distal values. 
Table V. Compositional Analysis of Lipid Extracts of Brush Border Membranes of Rat Proximal and Distal Colonocytes after 5, 10, and 15 wk of Administration of DMH or Diluent*

\begin{tabular}{|c|c|c|c|c|c|c|c|c|c|c|c|c|}
\hline \multirow[b]{3}{*}{ Parameter } & \multicolumn{12}{|c|}{ Duration of treatment ( $w k$ ) } \\
\hline & \multicolumn{4}{|l|}{5} & \multicolumn{4}{|l|}{10} & \multicolumn{4}{|l|}{15} \\
\hline & $\mathrm{C}(\mathrm{P})$ & DMH(P) & $C(D)$ & DMH(D) & $\mathrm{C}(\mathrm{P})$ & $\mathrm{DMH}(\mathrm{P})$ & $C(D)$ & DMH(D) & $\mathrm{C}(\mathrm{P})$ & DMH(P) & $C(D)$ & DMH(D) \\
\hline $\begin{array}{l}\text { Cholesterol/ } \\
\text { phospholipid } \\
(\mathrm{mol} / \mathrm{mol})\end{array}$ & $\begin{array}{r}0.78 \\
\pm 0.06\end{array}$ & $\begin{array}{r}0.72 \\
\pm 0.07\end{array}$ & $\begin{array}{r}0.90 \\
\pm 0.06\end{array}$ & $\begin{array}{r}0.79 \\
\pm 0.08\end{array}$ & $\begin{array}{r}0.85 \\
\pm 0.05\end{array}$ & $\begin{array}{r}0.96 \\
\pm 0.06\end{array}$ & $\begin{array}{r}0.96 \\
\pm 0.04\end{array}$ & $\begin{array}{r}0.87 \\
\pm 0.06\end{array}$ & $\begin{array}{r}0.79 \\
\pm 0.04\end{array}$ & $\begin{array}{r}0.78 \\
\pm 0.03\end{array}$ & $\begin{array}{r}0.87 \\
\pm 0.04\end{array}$ & $\begin{array}{r}0.83 \\
\pm 0.03\end{array}$ \\
\hline $\begin{array}{l}\text { Sphingomyelin/ } \\
\text { lecithin } \\
(\mathrm{mol} / \mathrm{mol})\end{array}$ & $\begin{array}{r}0.42 \\
\pm 0.04\end{array}$ & $\begin{array}{r}0.47 \\
\pm 0.02\end{array}$ & $\begin{array}{r}0.48 \\
\pm 0.05\end{array}$ & $\begin{array}{r}0.46 \\
\pm 0.03\end{array}$ & $\begin{array}{r}0.40 \\
\pm 0.03\end{array}$ & $\begin{array}{r}0.44 \\
\pm 0.06\end{array}$ & $\begin{array}{r}0.35 \\
\pm 0.03\end{array}$ & $\begin{array}{c}0.45 \\
\pm 0.04 \S\end{array}$ & $\begin{array}{r}0.39 \\
\pm 0.03\end{array}$ & $\begin{array}{r}0.45 \\
\pm 0.03\end{array}$ & $\begin{array}{r}0.41 \\
\pm 0.01\end{array}$ & $\begin{array}{c}0.47 \\
\pm 0.02 \S\end{array}$ \\
\hline $\begin{array}{c}\text { Protein/lipid } \\
(w t / w t)\end{array}$ & $\begin{array}{r}0.62 \\
\pm 0.10\end{array}$ & $\begin{array}{r}0.65 \\
\pm 0.06\end{array}$ & $\begin{array}{r}0.61 \\
\pm 0.07\end{array}$ & $\begin{array}{r}0.66 \\
\pm 0.07\end{array}$ & $\begin{array}{r}0.64 \\
\pm 0.07\end{array}$ & $\begin{array}{r}0.66 \\
\pm 0.03\end{array}$ & $\begin{array}{r}0.67 \\
\pm 0.08\end{array}$ & $\begin{array}{r}0.69 \\
\pm 0.07\end{array}$ & $\begin{array}{r}0.71 \\
\pm 0.04\end{array}$ & $\begin{array}{r}0.70 \\
\pm 0.06\end{array}$ & $\begin{array}{r}0.69 \\
\pm 0.05\end{array}$ & $\begin{array}{r}0.70 \\
\pm 0.06\end{array}$ \\
\hline $\begin{array}{c}\text { Saturation } \\
\text { index } \ddagger\end{array}$ & $\begin{array}{r}0.35 \\
\pm 0.02\end{array}$ & $\begin{array}{r}0.36 \\
\pm 0.01\end{array}$ & $\begin{array}{r}0.38 \\
\pm 0.02\end{array}$ & $\begin{array}{r}0.43 \\
\pm 0.02\end{array}$ & $\begin{array}{r}0.35 \\
\pm 0.02\end{array}$ & $\begin{array}{r}0.39 \\
\pm 0.02\end{array}$ & $\begin{array}{r}0.40 \\
\pm 0.01\end{array}$ & $\begin{array}{r}0.43 \\
\pm 0.01\end{array}$ & $\begin{array}{r}0.32 \\
\pm 0.02\end{array}$ & $\begin{array}{r}0.37 \\
\pm 0.02\end{array}$ & $\begin{array}{r}0.37 \\
\pm 0.01\end{array}$ & $\begin{array}{c}0.47 \\
\pm 0.03 \S\end{array}$ \\
\hline
\end{tabular}

Abbreviations: C, control; D, distal, P, proximal. * Values represent means \pm standard error of six separate preparations of each membrane except for the saturation index values listed under $\mathrm{C}(\mathrm{D})$ and $\mathrm{DMH}(\mathrm{D})$ for 15 weeks where 12 preparations were analyzed. $¥$ Calculated as (the total number of saturated residues)/(the sum of the number of each type of unsaturated residue multiplied by the number of double bonds in that residue). $\S P<0.05$ or less compared to control values of same segment.

phosphatidylcholine was no different in distal DMH-treated and control membranes. Although speculative, another possibility to explain the present observations might be that the anthroyloxy probes sense a particular lipid microenvironment and that the increased methyltransferase activity selectively alters this microenvironment. If this were true, gross lipid composition or studies with DPH might show no change. Further studies will, however, be necessary before this issue is resolved.

After 10 weeks of DMH, no significant difference in either component of lipid fluidity appeared to exist between distal DMH-treated and control membranes or their liposomes. Despite this latter finding, certain compositional differences were noted between the two distal membranes. The DMH-treated membranes had higher methyltransferase activity as well as a greater molar ratio of sphingomyelin/lecithin. This elevated ratio was secondary to an increased sphingomyelin content in the DMH membranes. Theoretically, the former difference might produce an increase in fluidity while the latter difference should result in a decrease in the fluidity of DMH-treated membranes $(46,51)$. In that no difference in fluidity could be detected, however, this data suggests that these differences either did not influence the lipid fluidity or served to offset each other, thereby, maintaining a relatively similar fluidity in both distal membranes.

Brush border membranes and liposomes prepared from distal colonocytes of animals which had received DMH for 15 wk had a lower dynamic component of fluidity than control prepara-

Table VI. Composition of Lipid Extracts of Brush Border Membranes of Rat Distal Colonocytes after 5, 10, and 15 wk of Administration of DMH or Diluent *

\begin{tabular}{|c|c|c|c|c|c|c|}
\hline \multirow[b]{3}{*}{ Component } & \multicolumn{6}{|c|}{ Total lipid of brush border membranes according to duration of treatment ( $w k)$} \\
\hline & \multicolumn{2}{|l|}{5} & \multicolumn{2}{|l|}{10} & \multicolumn{2}{|l|}{15} \\
\hline & Control & DMH & Control & DMH & Control & DMH \\
\hline & $\mathscr{D}(w t / w t)$ & $\%(w t / w t)$ & $\%(w t / w t)$ & $\%(w t / w t)$ & $\%(w t / w t)$ & $\%(w t / w t)$ \\
\hline Cholesterol & $24.71 \pm 1.38$ & $22.03 \pm 1.47$ & $26.69 \pm 0.84$ & $24.89 \pm 1.32$ & $25.01 \pm 0.72$ & $24.33 \pm 0.48$ \\
\hline Cholesterol esters & $3.56 \pm 1.19$ & $3.06 \pm 0.94$ & $2.12 \pm 0.78$ & $2.92 \pm 0.50$ & $2.25 \pm 0.81$ & $2.69 \pm 0.51$ \\
\hline Triacylglycerols & $3.53 \pm 0.91$ & $3.06 \pm 0.64$ & $2.61 \pm 0.62$ & $2.69 \pm 0.80$ & $2.76 \pm 0.48$ & $2.11 \pm 0.57$ \\
\hline Fatty acids & $17.47 \pm 1.42$ & $16.01 \pm 1.66$ & $12.29 \pm 0.54$ & $13.23 \pm 1.50$ & $14.81 \pm 0.47$ & $14.18 \pm 0.32$ \\
\hline Phosphatidylcholine & $20.66 \pm 2.18$ & $23.78 \pm 1.69$ & $26.18 \pm 1.14$ & $26.29 \pm 1.95$ & $24.63 \pm 1.39$ & $25.76 \pm 0.96$ \\
\hline Lysophosphatidylcholine & $0.60 \pm 0.20$ & $0.80 \pm 0.20$ & $0.80 \pm 0.17$ & $0.96 \pm 0.29$ & $0.75 \pm 0.14$ & $0.83 \pm 0.20$ \\
\hline Sphingomyelin & $9.64 \pm 0.47$ & $11.04 \pm 0.61$ & $9.18 \pm 1.07$ & $12.06 \pm 0.88 \ddagger$ & $9.98 \pm 0.37$ & $11.78 \pm 0.58$ \\
\hline Phosphatidylethanolamine & $17.58 \pm 1.07$ & $19.03 \pm 0.79$ & $17.23 \pm 0.74$ & $15.42 \pm 1.30$ & $15.67 \pm 0.33$ & $16.11 \pm 0.53$ \\
\hline Other phospholipids & $4.85 \pm 0.95$ & $3.00 \pm 0.99$ & $3.40 \pm 0.77$ & $2.50 \pm 0.67$ & $4.20 \pm 0.61$ & $3.06 \pm 0.81$ \\
\hline
\end{tabular}

* Values represent means \pm standard error of eight separate preparations of each membrane. $¥ P<0.05$ or less compared to control values of similar time periods. 
Table VII. Compositional Analysis of Total Fatty Acids of Brush Border Membranes of Rat Distal Colonocytes after 5, 10, and 15 wk of Administration of DMH or Diluent*

\begin{tabular}{|c|c|c|c|c|c|c|}
\hline \multirow[b]{3}{*}{ Fatty acids } & \multicolumn{6}{|c|}{ Duration of treatment ( $w k)$} \\
\hline & \multicolumn{2}{|l|}{5} & \multicolumn{2}{|l|}{10} & \multicolumn{2}{|l|}{15} \\
\hline & Control & DMH & Control & DMH & Control & DMH \\
\hline & \% by mass & \% by mass & \% by mass & \% by mass & \% by mass & \% by mass \\
\hline $14: 0$ & $0.63 \pm 0.06$ & $0.58 \pm 0.12$ & $0.31 \pm 0.15$ & $0.91 \pm 0.15$ & $0.27 \pm 0.03$ & $0.24 \pm 0.04$ \\
\hline $14: 1$ & $0.88 \pm 0.04$ & $0.86 \pm 0.06$ & $0.70 \pm 0.07$ & $0.90 \pm 0.04$ & $0.41 \pm 0.06$ & $0.46 \pm 0.03$ \\
\hline $16: 0$ & $25.88 \pm 0.28$ & $26.53 \pm 0.65$ & $24.34 \pm 0.59$ & $26.72 \pm 1.46$ & $23.28 \pm 1.47$ & $26.52 \pm 1.64$ \\
\hline $16: 1$ & $2.25 \pm 0.25$ & $2.36 \pm 0.24$ & $1.35 \pm 0.28$ & $2.03 \pm 0.04$ & $0.66 \pm 0.10$ & $0.77 \pm 0.12$ \\
\hline $18: 0$ & $16.70 \pm 0.47$ & $17.86 \pm 0.46$ & $16.45 \pm 0.65$ & $15.64 \pm 0.09$ & $17.14 \pm 1.22$ & $17.68 \pm 1.39$ \\
\hline 18:1 & $26.50 \pm 0.16$ & $26.16 \pm 0.20$ & $25.14 \pm 0.46$ & $23.85 \pm 1.53$ & $22.05 \pm 0.66$ & $23.75 \pm 0.61$ \\
\hline $18: 2$ & $14.04 \pm 0.31$ & $13.48 \pm 0.52$ & $12.22 \pm 0.13$ & $11.82 \pm 0.20$ & $13.57 \pm 0.51$ & $12.96 \pm 1.01$ \\
\hline $20: 4$ & $13.64 \pm 0.21$ & $12.18 \pm 0.63$ & $13.92 \pm 0.18$ & $12.66 \pm 0.57$ & $14.61 \pm 1.36$ & $9.98 \pm 0.75 \ddagger$ \\
\hline $22: 6$ & $0.96 \pm 0.16$ & $0.95 \pm 0.13$ & $0.80 \pm 0.17$ & $0.90 \pm 0.35$ & $2.17 \pm 0.20$ & $2.01 \pm 0.40$ \\
\hline $24: 0$ & $2.45 \pm 0.60$ & $2.07 \pm 0.61$ & $2.66 \pm 0.68$ & $1.91 \pm 0.50$ & $4.01 \pm 1.31$ & $3.76 \pm 0.47$ \\
\hline
\end{tabular}

* Values represent means \pm standard error of six separate preparations of each membrane for the 5- and 10-wk period and 12 separate membrane preparations of the 15 -wk period. $¥ P<0.01$ or less compared to control values at similar time periods.

tions. These membranes again had increased methyltransferase activity and a higher molar ratio of sphingomyelin/lecithin. Additionally, they were now found to possess a higher saturation index than control membranes. This difference should lead to a decrease in the fluidity of DMH-treated membranes relative to their control counterparts $(50,52)$, which agrees with the present findings. The higher saturation index in treated membranes was due to a decrease in arachidonic acid (20:4) compared to control values. Although the mechanism(s) responsible for these membrane fatty acid differences are presently unclear, further studies should prove interesting in that arachidonic acid is a precursor of prostaglandins and prostacyclin $\left(\mathrm{PGI}_{2}\right)$, substances previously shown to influence cellular proliferation (55-57).

These alterations noted in the dynamic component of fluidity and lipid composition of DMH-treated membranes and liposomes were restricted to the distal segment of the rat large intestine. This is particularly interesting in view of the marked predilection for the development of tumors in this colonic segment in animals treated with DMH $(4,8,58)$. The specific reason(s) that underlie this increased propensity to develop distal neoplasms in this cancer model remain unclear (8). This feature, taken together with the present data, however, suggests that the distal membrane alterations noted may more likely reflect the malignant transformation process itself than any effect of the drug per se.

Chemical carcinogenesis in this rat colon adenocarcinoma model, as in humans, appears to represent a multistage process $(59,60)$. Although speculative, the present data would suggest that alterations in the lipid fluidity and composition of plasma membranes of colonocytes may play a role in the early stage(s) of the malignant transformation process. Additional factor(s) would then be necessary for the development of carcinoma in certain of these cells. Further studies in this animal model of colon adenocarcinoma should elucidate the cellular mechanisms responsible for the membrane alteration noted in the present experiments as well as clarify their functional significance.

\section{Acknowledgments}

The authors thank Mrs. Donna Ellzey for her secretarial support and Ms. Kimberli Coleman for her excellent technical assistance. The authors are also grateful to Dr. L. Chowdhury for his assistance in the histologic examinations performed in this study.

This investigation was supported by grant CA36745 awarded by the National Cancer Institute.

\section{References}

1. Nicholson, G. L., and G. Poste. 1976. The cancer cell: dynamic aspects and modifications in cell surface organization. $N$. Engl. J Med. 295:197-203.

2. U. S. National Center for Health Statistics. 1972. Vital Statistics of the United States, 1968. Washington, D.C.: U. S. Government Printing Office.

3. Weisburger, J. H. 1971. Colon carcinogens: their metabolism and mode of action. Cancer. 28:60-70.

4. LaMont, J. T., and T. A. O'Gorman. 1978. Experimental colon cancer. Gastroenterology. 75:1157-1169.

5. Lingeman, C. H., and F. M. Garner. 1972. Comparative study of intestinal adenocarcinomas of animals and man. J. Natl. Cancer Inst. 48:325-346.

6. Schauer, A., T. Voellnagel, and F. Wildanger. 1969. Cancerisolierung des Rattendarmes durch 1,2 Dimethylhydrazin. Z. Gesamte. Exp. Med. 150:87-93.

7. Ward, J. M. 1974. Morphogenesis of chemically induced neoplasms of the colon and small intestine in rats. Lab. Invest. 30:505-513.

8. Freeman, H. J., Y. Kim, and Y. S. Kim. 1978. Glycoprotein metabolism in normal proximal and distal rat colon and changes associated with 1,2 dimethylhydrazine-induced colonic neoplasia. Cancer Res. 38: 3385-3390.

9. Ball, W. J., J. S. Salser, and M. E. Balis. 1976. Biochemical changes in premalignant intestines. Cancer Res. 36:3495-3498.

10. Ball, W. J., J. S. Salser, and M. E. Balis. 1976. Biochemical changes in preneoplastic rodent intestine. Cancer Res. 36:2686-2689. 
11. Brasitus, T. A., and R. S. Keresztes. 1984. Protein-lipid interactions in antipodal plasma membranes of rat colonocytes. Biochim. Biophys. Acta. 773:290-300.

12. Brasitus, T. A., and R. S. Keresztes. 1983. Isolation and partial characterization of basolateral membranes from rat proximal colonic epithelial cells. Biochim. Biophys. Acta. 728:11-19.

13. Brasitus, T. A. 1983. Lipid dynamics and protein-lipid interactions in rat colonic epithelial cell basolateral membranes. Biochim. Biophys. Acta. 728:20-30.

14. Schachter, D., U. Cogan, and R. E. Abbot. 1982. Asymmetry of lipid dynamics of human erythrocyte membranes studied with permeant fluorophores. Biochemistry. 21:2146-2150.

15. Inbar, M., N. Larnicol, L. Jasmin, Z. Mishal, Y. Augery, C. Rosenfeld, and G. A. Mathe. 1977. A method for the quantitative detection of human acute lymphocytic leukemia. Eur. J. Cancer. 13:12311236.

16. Obrenovitch, A., C. Sene, M. T. Negre, and M. Monsigny. 1978. Fluorescence polarization of 1,6-diphenyl-1,3,5-hexatriene embedded in membranes of mouse leukemia L1210 cells during the cell cycle. FEBS (Fed. Eur. Biochem. Soc.) Lett. 88:187-191.

17. Shinitzky, M., and M. Inbar. 1974. Differences in microviscosity induced by different cholesterol levels in the surface membrane lipid layer of normal lymphocytes and malignant lymphoma cells. J. Mol. Biol. 85:603-615.

18. Barkla, D. H., and P. J. M. Tutton. 1978. Ultrastructure of 1,2 dimethylhydrazine-induced adenocarcinomas in rat colon. J. Natl. Cancer Inst. 61:1291-1299.

19. Shamsuddin, A. K. M., and B. F. Trump. 1981. Colon epithelium. I. Lightmicroscopic, histochemical, and ultrastructural features of normal colon epithelium of male Fischer 344 rats. J. Natl. Cancer Inst. 66:375388.

20. Lowry, O. H., N. J. Rosebrough, A. L. Farr, and R. J. Randall. 1951. Protein measurements with the Folin phenol reagent. J. Biol. Chem. 193:265-275.

21. Brasitus, T. A., D. Schachter, and D. Mamouneas. 1979. Functional interaction of lipids and proteins in rat intestinal microvillus membranes. Biochemistry. 18:4136-4144.

22. Brasitus, T. A., A. R. Tall, and D. Schachter. 1980. Thermotropic transitions in rat intestinal plasma membranes studied by differential scanning calorimetry and fluorescence polarization. Biochemistry. 19: 1256-1261.

23. Brasitus, T. A., and D. Schachter. 1980. Lipid dynamics and lipid-protein interactions in rat enterocytes basolateral and microvillus membranes. Biochemistry. 19:2763-2769.

24. Brasitus, T. A., and D. Schachter. 1982. Cholesterol biosynthesis and modulation of membrane cholesterol and lipid dynamics in rat intestinal microvillus membranes. Biochemistry. 21:4136-4144.

25. Schachter, D., and M. Shinitzky. 1977. Fluorescence polarization studies of rat intestinal microvillus membranes. J. Clin. Invest. 59:536548.

26. Chen, L. A., R. E. Dale, S. Roth, and L. Brand. 1977. Nanosecond time-dependent fluorescence depolarization of diphenylhexatriene in dimyristoyl-lecithin vesicles and the determination of "microviscosity." $J$. Biol. Chem. 252:2163-2169.

27. Lakowicz, J. R., F. G. Prendergast, and D. Hogen. 1979. Differential polarized phase fluorometric investigations of diphenylhexatriene in lipid bilayers. Quantitation of hindered depolarizing rotations. Biochemistry. 18:508-519.

28. Lakowicz, J. R., F. G. Prendergast, and D. Hogen. 1979. Fluorescence anisotropy measurements under oxygen quenching conditions as a method to quantify the depolarizing rotations of fluorophores. Application to diphenylhexatriene in isotropic solvents and in lipid bilayers. Biochemistry. 18:520-527.

29. Heyn, M. P. 1979. Determination of lipid order parameters and rotational correlation times from fluorescence depolarization experiments. FEBS (Fed. Eur. Biochem. Soc.) Lett. 108:520-527.

30. Jahnig, F. 1979. Structural order of lipids and proteins in mem- branes: evaluation of fluorescence anisotropy data. Proc. Natl. Acad. Sci. USA. 76:6361-6365.

31. Vincent, M., B. DeForesta, J. Gallay, and A. Alfsen. 1982. Fluorescence anisotropy decays of $n-(9$ anthroyloxy) fatty acids in dipalmitoylphosphatidylcholine vesicles. Localization of the effects of cholesterol addition. Biochem. Biophys. Res. Commun. 107:914-921.

32. Van Blitterswijk, W. J., R. P. Van Hoeven, and B. W. Van der Meer. 1981. Lipid structural order parameters (reciprocal of fluidity) in biomembranes derived from steady-state fluorescence polarization measurements. Biochim. Biophys. Acta. 644:323-332.

33. Cogan, U., and D. Schachter. 1981. Asymmetry of lipid dynamics in human erythrocyte membranes studies with impermeant fluorophors. Biochemistry. 20:6396-6403.

34. Folch, J., M. Lees, and G. A. Sloane-Stanley. 1957. A simple method for the isolation and purification of total lipids from animal tissues. J. Biol. Chem. 226:497-509.

35. Zlatkis, A., B. Jak, and A. J. Boyle. 1953. A new method for the determination of serum cholesterol. J. Lab. Clin. Med. 41:486-492.

36. Ames, B. N., and D. T. Dubin. 1960. The role of polyamines in the neutralization of bacteriophage deoxyribonucleic acid. J. Biol. Chem. 235:769-775.

37. Katz, S. S., G. G. Shippley, and D. M. Small. 1976. Physical chemistry of the lipids of human atherosclerotic lesions: demonstration of a lesion intermediate between fatty streaks and advanced plaques. $J$. Clin. Invest. 58:200-211.

38. Gartner, S. L., and G. V. Vahouny. 1972. Effects of epinephrine and cyclic 3', 5'-AMP on perfused rat hearts. Am. J. Physiol. 222:11211124.

39. Hirata, F., O. H. Viveros, E. J. Diliberto, Jr., and J. Axelrod. 1978. Identification and properties of two methyltransferases in conversion of phosphatidylethanolamine to phosphatidylcholine. Proc. Natl. Acad. Sci. USA. 75:1718-1721.

40. Crews, F. T., F. Hirata, and J. Axelrod. 1980. Identification and properties of methyltransferases that synthesize phosphatidylcholine in rat brain synaptosomes. J. Neurochem. 34:1491-1498.

41. Katyal, S. L., and B. Lombardi. 1974. Quantitation of phosphatidyl $N$-methyl and $N, N$-dimethylaminoethanol in liver and lung of $\mathrm{N}$ methylaminoethanol fed rats. Lipids. 9:81-86.

42. Schneider, W. J., and D. E. Vance. 1979. Conversion of phosphatidylethanolamine to phosphatidylcholine in rat liver: partial purification and characterization of the enzymatic activities. J. Biol. Chem. 254:3886-3891.

43. Audubert, F., and D. E. Vance. 1983. Pitfalls and problems in studies on the methylation of phosphatidylethanolamine. J. Biol. Chem. 258:10695-10701.

44. Barthod, S. W., and A. M. Jonas. 1977. Morphogenesis of early 1,2-dimethylhydrazine-induced lesions and latent period reduction of colon carcinogenesis in mice by a variant of citrobacter freundii. Cancer Res. 37:4352-4360.

45. Brasitus, T. A., and R. S. Keresztes. 1983. Glycoprotein metabolism in rat colonic epithelial cell population with different proliferative activities. Differentiation. 24:239-244.

46. Dudeja, P. K., and T. A. Brasitus. 1985. Phospholipid methylation in rat colonic brush border membranes influences fluidity. Fed. Proc. 44:858. (Abstr.)

47. Lineweaver, H., and D. Burk. 1934. Determination of enzyme dissociation constants. J. Am. Chem. Soc. 56:658-666.

48. Chapman, D., and S. A. Penkett. 1966. Nuclear magnetic resonance spectroscopic studies of the interaction of phospholipids with cholesterol. Nature (Lond.). 211:1304-1305.

49. Hubbell, W. L., and H. M. McConnell. 1971. Molecular motion in spin labelled phospholipids and membranes. J. Am. Chem. Soc. 93 314-326.

50. Shinitzky, M., and Y. Barenholz. 1978. Fluidity parameters of lipid regions determined by fluorescence polarization. Biochim. Biophys. Acta. 515:367-394.

51. Shinitzky, M., and Y. Barenholz. 1974. Dynamics of the hydro- 
carbon layer in liposomes of lecithin and sphingomyelin containing dicetylphosphate. J. Biol. Chem. 249:2652-2657.

52. Oldfield, E., and D. Chapman. 1971. Effect of cholesterol and cholesterol derivatives on hydrocarbon chain mobility in lipids. Biochem. Biophys. Res. Commun. 43:610-616.

53. Lentz, B. R., Y. Barenholz, and T. E. Thompson. 1976. Fluorescence depolarization studies of phase transitions and fluidity in phospholipid bilayers. I. Single component phosphatidylcholine liposomes. Biochemistry. 15:4521-4528.

54. Hirata, F., and J. Axelrod. 1978. Enzymatic methylation of phosphatidylethanolamine increases erythrocyte membrane fluidity. Nature (Lond.). 275:219-220.

55. Craven, P. A., and F. R. DeRubertis. 1983. Pattern of prostaglandin synthesis and degradation in isolated superficial and proliferative colonic epithelial cells compared to residual colon. Prostaglandins. 26: 583-604.
56. Craven, P. A., and F. R. DeRubertis. 1980. Early alterations in rat colonic mucosal cyclic nucleotide metabolism and protein kinase activity induced by 1,2 dimethylhydrazine. Cancer Res. 40:4589-4598.

57. Morisaki, N., J. A. Lindsey, G. E. Milo, and D. G. Cornewell. 1983. Fatty acid metabolism and cell proliferation. III. Effect of prostaglandin biosynthesis either from exogenous fatty acid or endogenous fatty acid release with hydralazine. Lipids. 18:349-352.

58. Toth, B., L. Malick, and H. Shimizu. 1976. Production of intestinal and other tumors by 1,2 dimethylhydrazine dihydrochloride in mice. Am. J. Clin. Pathol. 84:69-86.

59. Armitage, P., and R. Doll. 1954. The age distribution of cancer and a multi-stage theory of carcinogenesis. Br. J. Cancer. 8:1-12.

60. Maskens, A. P. 1981. Confirmation of the two-step nature of chemical carcinogenesis in the rat colon adenocarcinoma model. Cancer Res. 41:1240-1245. 